\title{
Die mesophytische Flora der Saurierlagerstätte am Tendaguru (Tansania) Erste Ergebnisse
}

\author{
Eberhard Kahlert ${ }^{1}$, Stephan Schultka ${ }^{1}$ \& Herbert Süß ${ }^{1}$
}

Mit 4 Tafeln und 1 Abbildung

\section{Zusammenfassung}

Abgesehen von einem unreifen Araukarienzapfen, der 1927 von Gothan kurz beschrieben wurde, werden erstmalig Pflanzenreste aus den Jura-Kreide-Grenzschichten des Tendaguru bekannt gemacht. Verkieselte Hölzer vor allem aus kreidezeitlichen Schichtabschnitten repräsentieren die für den Jura üblichen Koniferengruppen wie Taxodiaceae, Cupressaceae und Taxaceae. Daneben konnten Ginkgoaceae nachgewiesen werden. Fusit ist nicht selten, meist aber sehr schlecht erhalten, bis auf ein Stück, das die Merkmale einer wahrscheinlich neuen Art von Glyptostroboxylon, einer Taxodiacee, zeigt. Naturmazerate von Kutikulen sind in den mittleren Saurier-Mergeln (tieferes Kimmeridge) häufig und können möglicherweise Ginkgophyten des Baiera/Sphenobaiera-Typs zugerechnet werden. Damit scheint die Flora von Tendaguru auf den ersten Blick von Gymnospermen extrem stark dominiert zu sein. Diese Dominanz ist wahrscheinlich auf taphonomische Prozesse und auf die selektive Probennahme während der Grabungsexpedition in den Jahren 1909-1913 zurückzuführen. So erscheinen neue Profilaufnahmen im Gelände unumgänglich, um ein differenzierteres Bild der jurassisch-kretazischen Flora des östlichen Afrika - die die Ernährungsgrundlage der meisten Dinosaurier vom Tendaguru bildete - zu entwickeln und phytogeographische Beziehungen genauer fassen zu können.

Schlüsselwörter: Saurier-Mergel, Jura, Kreide, Kutikulen, Fusit, Kieselhölzer.

\begin{abstract}
Little is known about the Jurassic flora of East Africa. Therefore a preliminary account on plant remains from the wellknown „Saurierlagerstätte“ of Tendaguru is presented. Specimens of silicified wood represent typical conifers, such as Taxodiaceae, Cupressaceae and Taxaceae, but also demonstrate the presence of Ginkgoales. Fusite is very common, but mostly not well preserved, except for one specimen which shows the characteristics of possibly a new species of the Taxodiacean genus Glyptostroboxylon. Natural macerated cuticules are abundant in the „middle Saurier-Mergel“ (Lower Kimmeridgian) and they at least in part seem to belong to Ginkgophytaleans of the Baiera/Sphenobaiera-group. At first glance the composition of the flora of Tendaguru seems to be biased towards a predominance of Gymnosperms. This is not only a result of taphonomical processes, but also of selective sampling in 1909-1913. Preliminary observations support the opinion that further field work must be carried out if we would like to obtain a clearer „picture“ of the Jurassic-Cretaceous flora that formed the diet of herbivorous dinosaurs.
\end{abstract}

Key words: „Saurier-Mergel“, Late Jurassic, Early Cretaceous, cuticles, fusite, silicified wood.

\section{Einleitung}

Aus den Sedimentationsfolgen des östlichen Afrika ist bisher nur sehr wenig über fossile Floren bekannt geworden. Vor allem die berühmten Saurier-Fundstätten am Tendaguru an der Wende vom Jura zur Kreide lieferten nur wenige, unbestimmte Pflanzenfossilien. Daß aber in den Sedimentationsabfolgen um den Tendaguru herum vermehrt Pflanzenreste vorhanden sind, belegen die Erwähnungen in Verbindung mit der Be- arbeitung der Invertebraten- und Vertebratenfunde. So weist Dietrich (1914) auf ,... reichliche pflanzliche Einstreu...“ in den beiden unteren marinen Zwischenhorizonten („Nerineen- und smeei-Schicht") hin. Er spricht in diesem $\mathrm{Zu}$ sammenhang sogar von „Häckselsandstein“. Aus dem „oberen Saurier-Mergel" und dem „schwarzi-Horizont" beschreibt Hennig (1914) „,...vielfach fossile Hölzer, und zwar stellenweise Stämme von beträchtlicher Länge...". Auch für den Newala-Sandstein, als lithologischer Sedi-

\footnotetext{
${ }^{1}$ Museum für Naturkunde, Institut für Paläontologie, Invalidenstr. 43, D-10115 Berlin, Germany.

e-mail: stephan.schultka@rz.hu-berlin.de

Erhalten February 1999, angenommen June 1999
} 
mentationseinheit der Makondeschichten, werden verbreitet größere Stammstücke von Kieselhölzern angegeben (Hennig 1914). Stratigraphisch gehören diese jüngsten Schichten in der Gesamtabfolge nach Hennig (1937) ins obere Apt.

Für den oberen Saurier-Mergel führen Hennig (1914) und Zwierzycki (1914) die Flora als einen Beleg für Wealden-Alter an. Sie stützen sich dabei auf Potonié, der das Wealden-Alter aufgrund des Fundes einer „oberflächlich herausgewitterten, ausgezeichnet erhaltenen Frucht" bestätigt (Hennig 1914). In der Folgezeit wurde diese Fruktifikation von Gothan (1927) unter der Bezeichnung Conites araucarioides näher beschrieben. Es handelt sich dabei um einen verkieselt erhaltenen, unreifen Araukarienzapfen (Stockey 1982), der deutlich Abrasionserscheinungen zeigt. Aitken (1961) kam zu dem Ergebnis, daß die mittleren und oberen Saurier-Mergel in das Kimmeridge zu stellen sind (weiteres zur Stratigraphie siehe Heinrich 1999, in diesem Heft).

Vor allem die Frage nach der Ernährungsweise der Großsaurier in der letzten Zeit regte dazu an, sich näher mit der Flora der ,TendaguruSchichten" (im Sinne von Janensch 1914) zu beschäftigen, da die Sauropoden vornehmlich Pflanzenfresser waren (Weaver 1983). Dabei ergeben sich allerdings eine Reihe von biomechanischen Problemen bei der Nahrungsaufnahme und der Nahrungsmengen, die zur Aufrechterhaltung der Körperfunktionen verschlungen werden mußten. So ist u. a. die Halsstellung von Bedeutung, die es zumindest ausgewachsenen Tieren sehr schwer gemacht haben dürfte, Pflanzenorgane der Bodenvegetation aufgenommen zu haben. Dadurch wird der Zugang zur verfügbaren Biomasse wie auch der Artenzahl potentieller Futterpflanzen erheblich eingeschränkt. Dies würde allerdings nicht unbedingt für die juvenilen Tiere gelten, die sich möglicherweise von Pflanzen ernährten, die den ausgewachsenen Tieren nicht mehr zur Verfügung standen. Ebenso ist die Möglichkeit der Aufnahme von tierischer Nahrung nicht außer Acht zu lassen.

Dieser Aspekt könnte der Lösung eines weiteren Problems näher kommen, nämlich der ausreichenden Versorgung mit potentiellen Energielieferanten. Völlig ungeklärt ist darüberhinaus, wie die Großsaurier ihren Bedarf an Calcium und Natrium zum Aufbau und Erhaltung ihres Stoffwechsels deckten. Es ist nicht auszuschließen, daß ein nicht geringer Teil dieser Stoffe durch die gelegentliche Aufnahme von Erden, die mit Spurenelementen angereichert waren, bzw. von Salzkrusten gedeckt wurde.
Unter Berücksichtigung der im Allgemeinen sehr hartlaubigen Pflanzen des Erdmittelalters mit ihren vermutlich hohen Gehalten an Harzen, ätherischen Ölen und pflanzlichen Giften stellt sich die Frage nach den biochemischen Aufschlußmöglichkeiten der Nahrung im MagenDarmtrakt der Saurier. Untersuchungen zur Flora der Tendaguru-Schichten könnten dazu beitragen, die Arten der verfügbaren, potentiellen Futterpflanzen näher einzugrenzen.

Aufbereitungen von Sedimentproben aus den Grabungen von Janensch et al. aus den Jahren 1909-1913 lieferten neben Kleinsäugerresten (Heinrich 1998) auch Mikrofossilien. Dies wurde zum Anlaß genommen, das noch vorhandene Probenmaterial auf pflanzliche Mikro- wie Makroreste hin zu untersuchen.

\section{Material}

Zum Zeitpunkt der Aufsammlung des vorliegenden Materials durch einheimische Hilfskräfte in den Jahren 1909 bis 1913 gab es für das Gebiet um den Tendaguru noch keine gesicherten stratigraphischen Profile. Obwohl Janensch wie Hennig die Zuverlässigkeit der angelernten Ausgräber betonen, ist eine genaue Stellung im geologischen Profil somit nicht immer gegeben und die stratigraphische Einstufung zumindest sehr schwierig (Probleme der stratigraphischen Einordnung siehe Heinrich 1999, in diesem Heft). Die fazielle Deutung schwankt zwischen ,lagunär" für die Saurier-Mergel und „marin“ für die smeei-bzw. schwarzi-Schicht.

Zudem handelt es sich bei den Kieselhölzern sowie den calcitisch/dolomitisch erhaltenen Stammresten vorwiegend um Lesesteine, wie die Verwitterungsrinde vieler Stücke belegt. Abrasionserscheinungen, wie sie bereits bei dem von Gothan (1927) beschriebenen Araukarienzapfen erwähnt werden, weisen auf Umlagerungsvorgänge nach dem Herauswittern aus dem Anstehenden hin. So ist es nicht verwunderlich, daß sich offensichtlich unterschiedlich alte Kieselhölzer unter den Aufsammlungen um den Tendaguru herum finden. Es wurde daher von vornherein nur Material für diese Arbeit herangezogen, dessen Herkunft als annähernd gesichert gelten darf Dabei zeigte sich, daß fast alle Kieselhölzer aus der schwarzi-Schicht zu stammen scheinen, also aus kreidezeitlichen Schichten, die die eigentlichen, Saurierknochen führenden Schichten überlagern.

Nur einige wenige Kieselholzreste stammen aufgrund ihrer Erhaltung vermutlich aus dem Anstehenden. Bei den calcitisch bis dolomitisch erhaltenen Stammresten ist die Herkunft etwas sicherer. Die geringe Widerstandsfähigkeit gegen Erosion läßt auf das Vorkommen am Fundort schließen. Ein weiter Transport oder eine Kondensation über längere, geologische Zeiträume kann ausgeschlossen werden. Die Herkunft aus den jura-kreidezeitlichen Grenzschichten des Gebietes um den Tendaguru (,Tendaguru-Schichten“ Janensch 1914) dürfte daher als wahrscheinlich gelten (Abb. 1).

Kohlig erhaltene Pflanzenreste liegen durchweg als Häcksel in mehreren Sedimentproben vor. Sie stammen fast alle aus dem Cyrenen-Mergel als Teil der mittleren SaurierMergel sowie den Übergangsschichten zwischen der smeeiSchicht und dem oberen Saurier-Mergel. Nach Aitken (1961) gehören der mittlere Saurier-Mergel ins tiefere Kimmeridge, während der obere Saurier-Mergel in das obere Kimmeridge einzustufen ist. Eine Probe mit größeren Achsenresten stammt vermutlich aus der schwarzi-Schicht, des- 

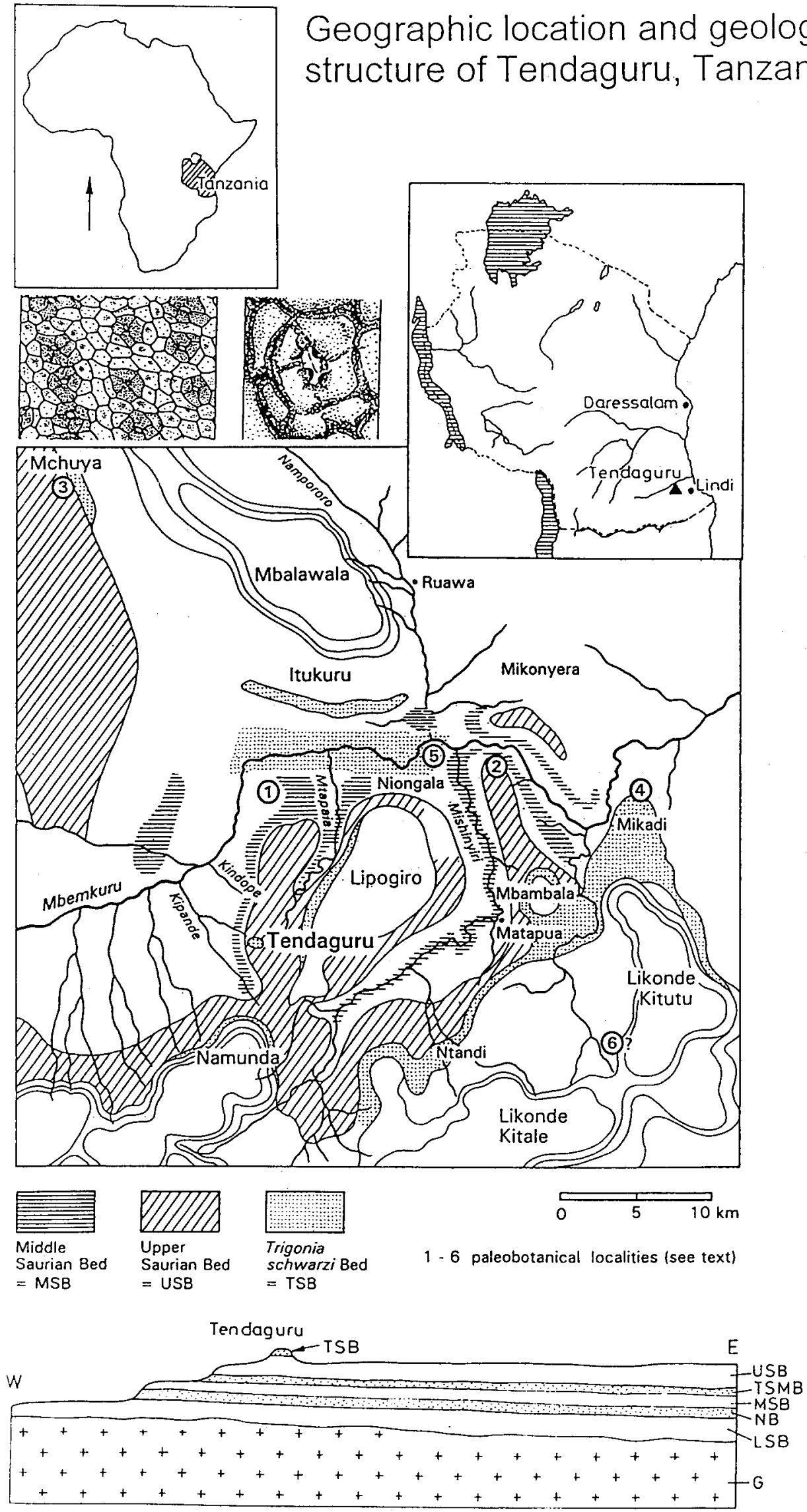

\section{Geographic location and geological} structure of Tendaguru, Tanzania
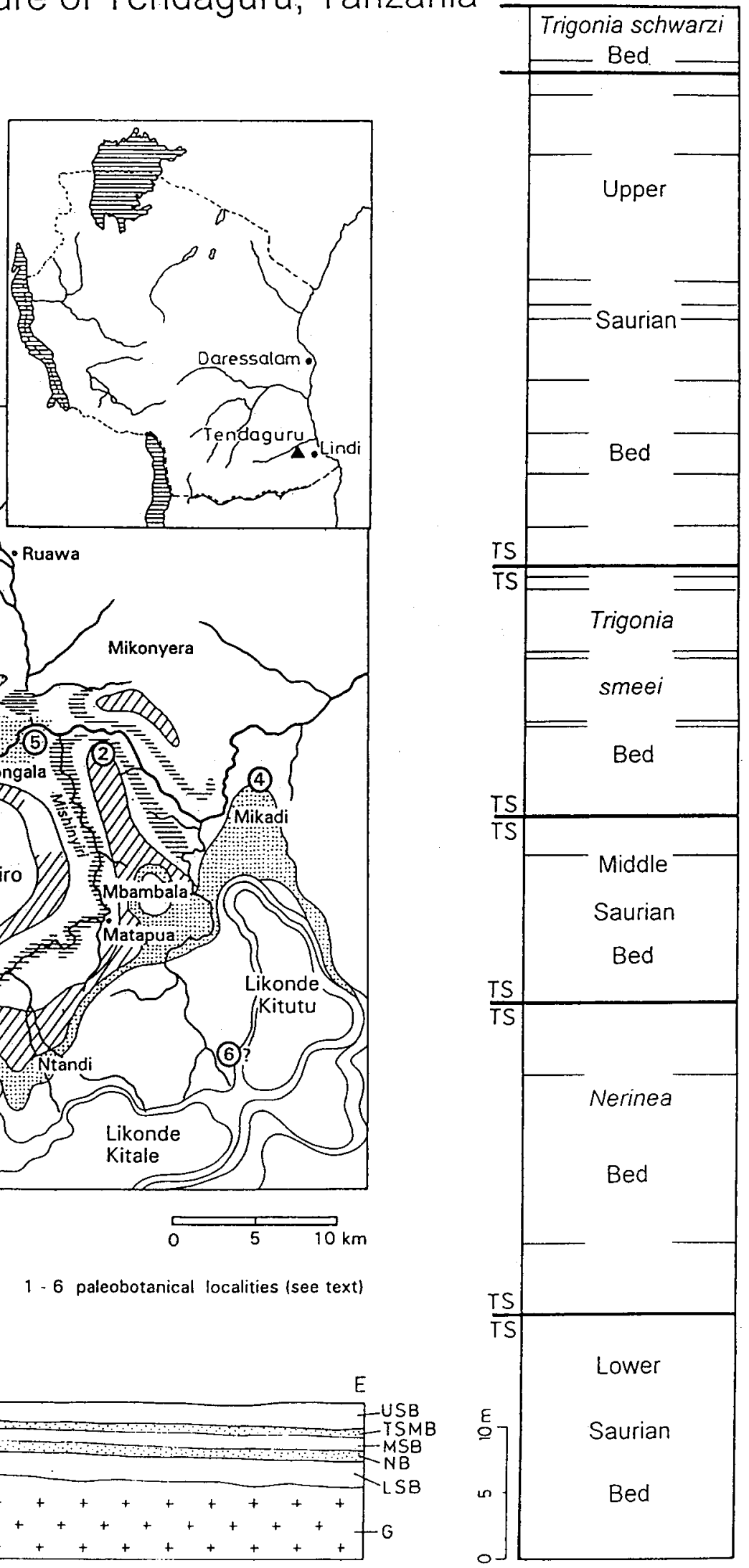

Abb. 1. Lageskizze des Tendaguru und geologische Übersichtskarte der Umgebung mit den Fundpunkten der in der Arbeit erwähnten Pflanzenresten (Näheres siehe Heinrich 1999, in diesem Heft), die Zeichnung der Kutikule bezieht sich auf den Typ ,A“ Fig. 1. Geographical and geological map of the Tendaguru area with geological sections and the location of paleobotanical sites mentioned in the present publication (see also Heinrich 1999, this vol.). Cuticle type A is shown in the sketch 
sen Alter von Aitken (1961) als Hauterive bis tiefes Apt angegeben wird.

Die kohligen Makroreste scheinen z. T. in Spülsäumen konzentriert zu sein und sind unbestimmbar. Solche Pflanzenhäcksel und Fusite, als Beleg häufiger Brandereignisse im Hinterland, kommen überall vor, ausreichend gut erhalten war bisher aber nur ein Fusit aus dem mittleren Saurier-Mergel. Aus den gleichen Schichten stammen auch die einzigen auswertbaren Kutikulen. Diese fielen vor allem bei der Aufbereitung des Cyrenen-Mergels vom Kitukituki-Bach auf Mikrofossilien an. Meist handelt es sich um sehr kleine, gering inkohlte bzw. naturmazerierte Fetzen, doch gelegentlich sind größere, zusammenhängende Kutikulenteile sowie fast vollständige, aber sehr kleine Blättchen überliefert, die dann Ober- und Unterseite zeigen. Haare oder Trichome konnten nur in einem Falle beobachtet werden, Fußzellen sind nich nachweisbar. Das Fehlen von Haaren dürfte nur teilweise auf die Erhaltung zurückzuführen sein, zum größeren Teil kann man wohl von primär haar- bzw. trichomlosen Kutikulen ausgehen.

Ebenfalls aus diesem Schichtkomplex stammen die wenigen bisher auswertbaren Palynomorphen-Assoziationen, die von Koniferen auffällig stark dominiert werden. Daneben treten Pteridophytensporen relativ selten auf, vergesellschaftet vor allem noch mit Lebermoosen und Moosen (Schrank 1999, frdl. mündl. Mitteilung).

Alle Pflanzenreste hatten zumindest teilweise einen längeren Transport hinter sich, was sich u. a. in der starken Zerhäckselung der Pflanzenreste zeigt. Die Naturmazeration der Epidermenfetzen belegt Abbauprozesse vor der Fossilisation. Die Stammreste zeigen selbst bei widerstandsfähigeren Holzkörpern deutliche Abbauerscheinungen (z.B. durch Pilze), was ihre Bestimmung sehr erschwert. Einige fusitisierte Hölzer waren bereits vor der Verbrennung soweit ,vermulmt“, daß kaum noch einzelne Tracheiden im Zellverband verblieben sind. Insektenbefall ist durch Fraßgänge und ?Koprolithen nachgewiesen. Einige Hölzer waren von Teredoartigen Organismen besiedelt (Taf. 1: 1), was längeres Flotieren der Hölzer im Wasser belegt. Daneben fand sich bisher nur eine unbestimmbare Zapfenschuppe (Taf. 1:2).

\section{Die Hölzer}

Alle zumindest näherungsweise bestimmbaren pflanzlichen Makroreste gehören zu den Gymnospermen. Während man bei den Kutikulen die taxonomische Zugehörigkeit nur vermuten kann, sind viele Holzreste bis zur Gattung bestimmbar. So sind bisher Cycadeen, Ginkgoaceen, Taxodiaceen, Cupressaceen und Taxaceen nachgewiesen.

\section{Cycadales}

Vom Plateaurand, nördlich des Tendaguru, zwischen den Bächen Kintope und Mtapaia (Abb. 1, Nr. 1), wahrscheinlich aus der smeei-Schicht (mittleres bis oberes Kimmeridge), stammt ein hellgrauer, schwach dolomitischer Stammrest, der zur Gattung Cycadoxylon Renault (Cycadaceae) gehört.

Das leicht konische Stammsegment ist etwa $30 \mathrm{~cm}$ lang und hat an seinem stärksten Ende einen Durchmesser von etwa $7 \mathrm{~cm}$. Der Holzteil um den Markkörper besteht aus 4 Leitelementringen (Taf. 2: 3). Der Markkörper hat einen Durchmesser von $8 \mathrm{~mm}$, seine Zellen sind vollständig rekristallisiert. Die Leitelementringe sind 12,18 und $12 \mathrm{~mm}$ breit, ein vierter Ring ist bis auf wenige Reste nicht mehr erhalten. Die Leitelementringe sind jeweils durch eine stark zusammengepreßte Zone parenchymatischer Zellen voneinander getrennt. In den Leitelementringen sind die Tracheiden des Holzgewebes in radialer Anordnung nur noch in wenigen, locker stehenden tangentialen Reihen beiderseits der schmalen Markstrahlen unzerstört vorhanden. Die im Umriß auffällig kreisförmigen Tracheiden messen 25-35 $\mu \mathrm{m}$ im Durchmesser. An einigen Stellen der Längsschnitte konnten auf den radialen Tracheidenwänden einreihig übereinanderstehende Hoftüpfel und Spiralverdickungen nachgewiesen werden. Die Markstrahlen sind 1-2 Zellen breit und sehr niedrig. Bedingt durch die Erhaltung konnte ihre genaue Höhe nicht exakt nachgewiesen werden. Die Markstrahlzellen sind 10-20 $\mu \mathrm{m}$ hoch. Auf dem Querschnitt des Stammes sind im zweiten Leitelementring mehrere breite, keilförmige Markstrahlen vorhanden, deren Zellen nicht erhalten sind. Die bereits weit fortgeschrittene Mineralisierung des Stammrestes und die damit verbundene Zersetzung des Gewebes macht eine weiterführende Bestimmung unmöglich.

Tafel 1. 1. Treibholz mit Teredo-ähnlichen Bohrgängen (Inv.-Nr. 1999/592), ?smeei-Schicht, Tendaguru, 1:1. 2. unbestimmbare Fruchtschuppe einer Konifere (Inv.-Nr. 1999/593), Cyrenen-Mergel der Mittleren Saurier-Mergel, Kitukituki-Bach, $2: 1.3$. unbestimmbare Koniferennadel (Inv.-Nr. 1999/594), konglomeratischer Sandstein über der smeei-Schicht, Tingutinguti-Bach, 2:1 $($ Balken $=1 \mathrm{~cm})$. 4. Fusit einer Taxodiaceen-Achse neben einer Cyrene (Inv.-Nr. 1999/595), Cyrenen-Mergel der mittleren Saurier-Mergel, Kitukituki-Bach, 2:1. 5. Glyptostroboxylon sp. (Ausschnitt aus Fig. 4), radialer Bruch, mehrere, bis zu 5 Zellen hohe Markstrahlen zeigend, REM, 160:1 (Balken =100 $\mu \mathrm{m}$ ). 6. Glyptostroboxylon sp. (Ausschnitt aus 5), Kreuzungsfelder mit bis zu 13 behöften Tüpłeln, REM, 1000:1 (Balken $=10 \mu \mathrm{m})$

Plate 1. 1. Destructive borings by 'Teredo-like' animals in a piece of driftwood (Inv.-Nr. 1999/592), ?Smeei-Beds, Tendaguru, 1:1. 2. Indeterminate coniferous cone-scale (Inv.-Nr. 1999/593), Cyrena-Marl of the Middle Saurian Beds, Kitukituki-brook, 2:1. 3. Indeterminate coniferous leaf (Inv.-Nr. 1999/594), conglomeratic sandstone above the Smeei-Beds, Tingutinguti-brook, 2:1 (scale bar $=1 \mathrm{~cm}) .4$. Fusite of an axis (taxodiacean type) with Cyrena (Inv.-Nr. 1999/595), Cyrena-Marl of the Middle Saurian Beds, Kitukituki-rook, 2:1. 5. Glyptostroboxylon sp. (deatil from fig. 4), radial fracture, showing xylem rays, some 5 cells high, SEM, 160:1 (scale bar $=100 \mu \mathrm{m})$. 6. Glyptostroboxylon sp. (detail from fig. 5), with up to 13 cross-field pits, SEM, $1000: 1($ scale bar $=10 \mu \mathrm{m})$ 


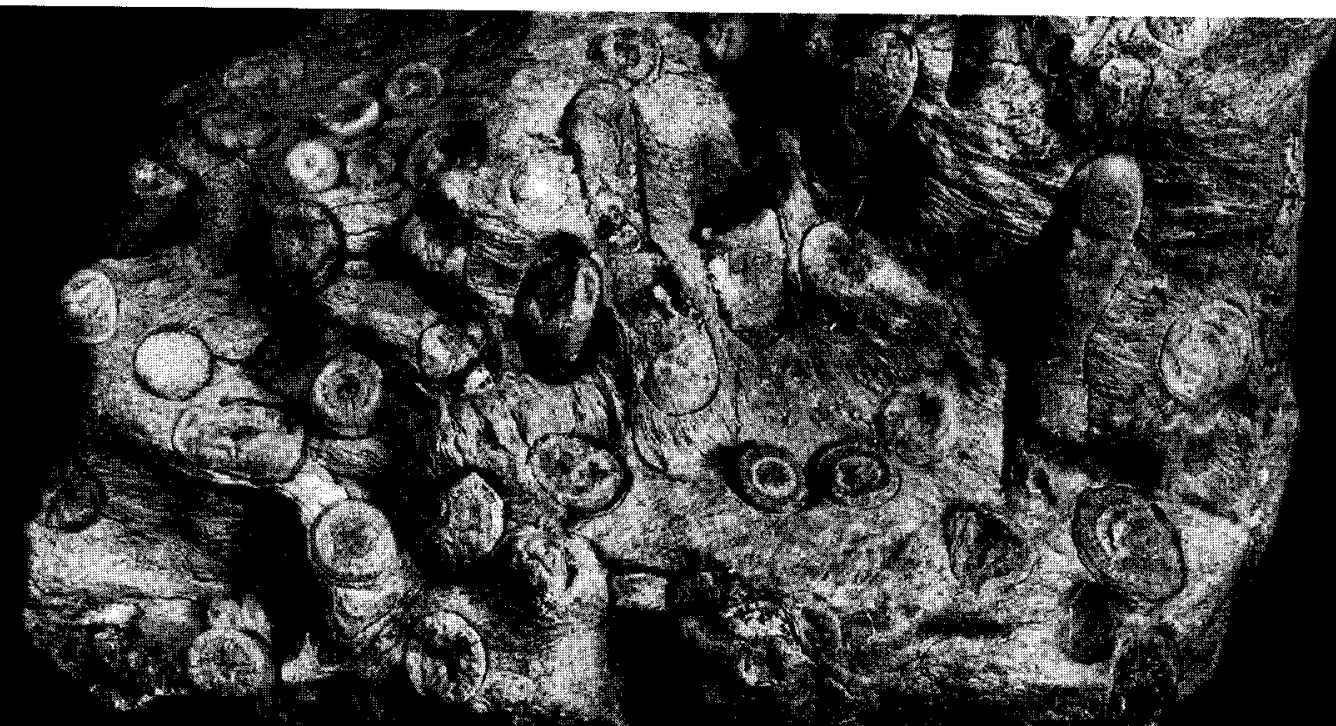

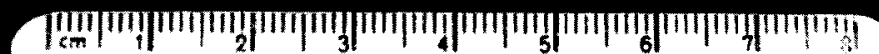

1
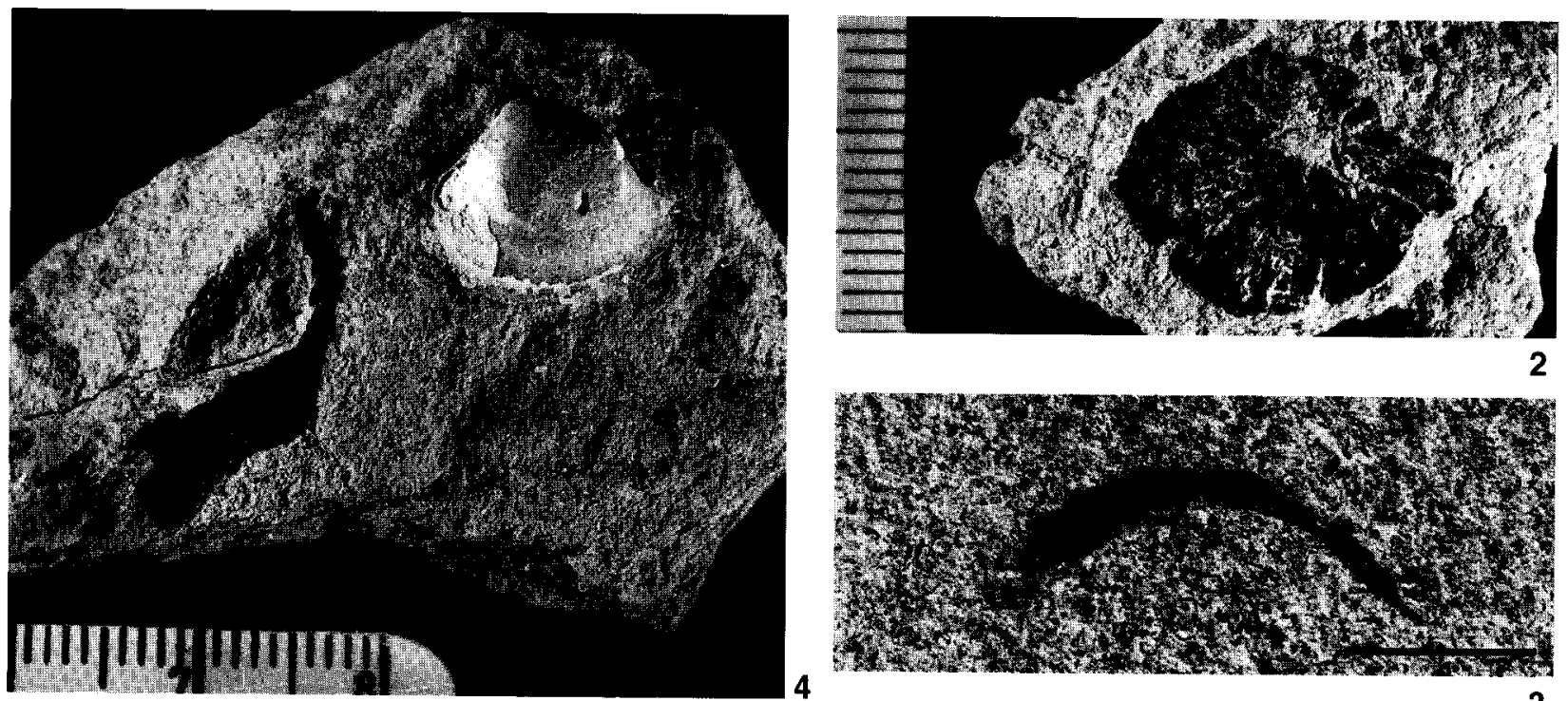

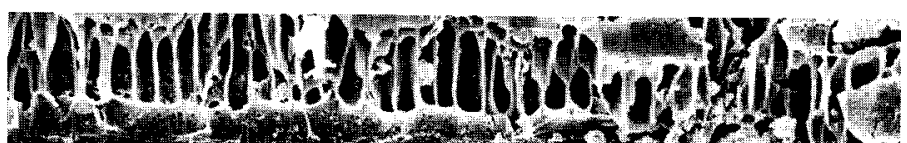

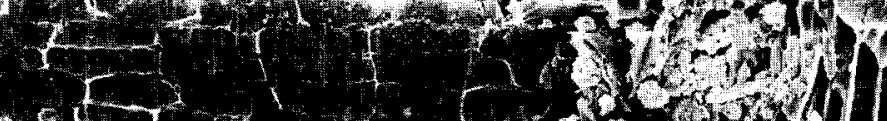

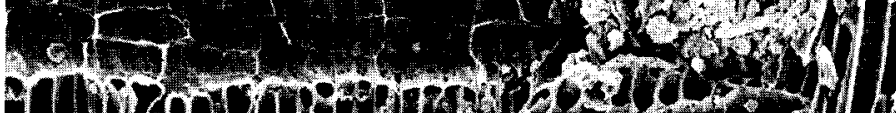

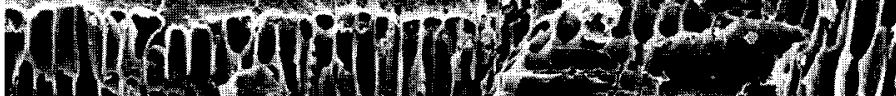

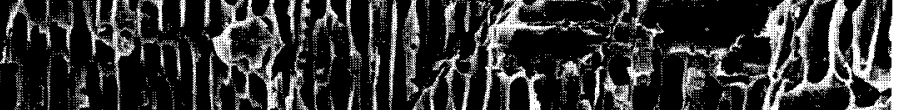
(1)

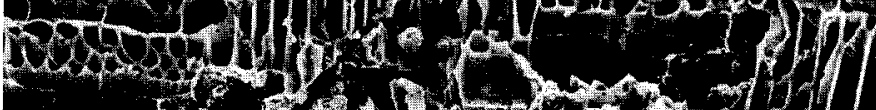

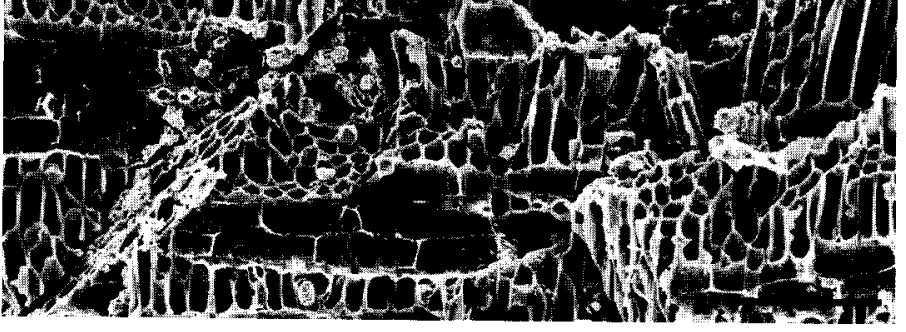

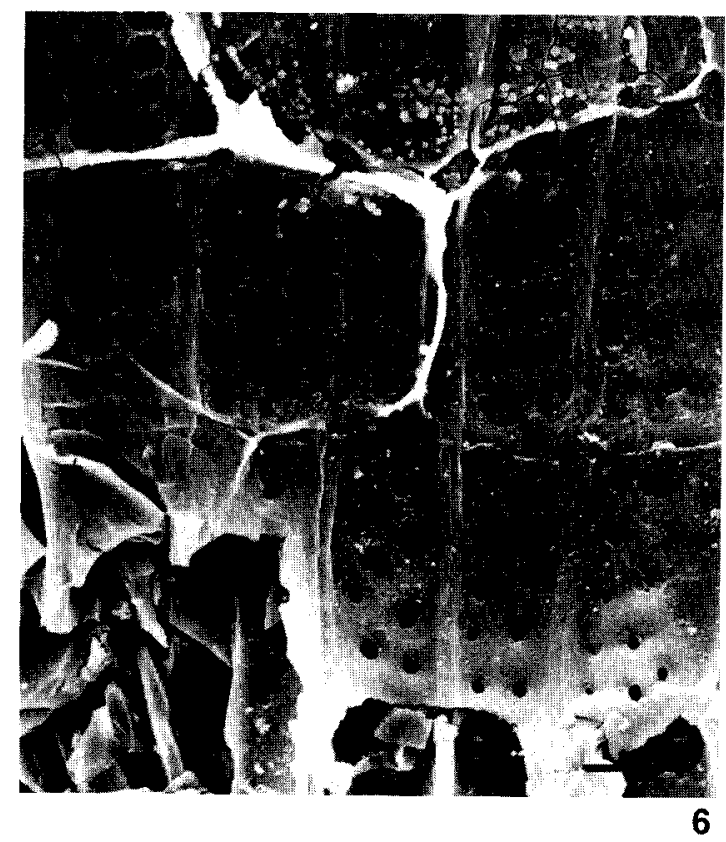




\section{Ginkgoales}

Zwei Holzreste der Gattung Ginkgoxylon Chudajberdiev (Ginkgoaceae) wurden vermutlich in den schwarzi-Schichten (?Apt) aufgesammelt. Ein Fundpunkt liegt etwa $20 \mathrm{~km}$ nordöstlich vom Tendaguru am Fuße des Mbambala-Massivs bei Kihendye (Abb. 1, Nr. 2), während sich der zweite auf dem Plateau von Mchuya, etwa $30 \mathrm{~km}$ nördlich vom Tendaguru befindet (Abb. 1, Nr. 3).

Die verkieselten Stücke sind etwa 25 bzw. $8 \mathrm{~cm}$ lang und 12 bzw. $4,5 \mathrm{~cm}$ breit. Bei beiden Stücken handelt es sich nur um Stammsegmente. Zuwachszonen sind schwach ausgebildet und ihre Grenzen nur durch einige radial verkürzte Tracheiden erkennbar. Der Übergang vom Frühzum Spätholz erfolgt sehr allmählich. Die Grundmasse des Holzes wird durch Tracheiden gebildet, die auf dem Querschnitt in radialen Reihen angeordnet sind (Taf. 2: 5) und mit auffällig verschieden großen Tracheidendurchmessern unmittelbar nebeneinander liegen (Taf. 2: 6). Auf den Längswänden sind gelegentlich mehr oder weniger tropfenförmige, Idioblasten-artige Zellen erkennbar. Die Holzstrahlen sind einreihig und 1-10 Zellen hoch. Die Betüpfelung der Tracheidenlängswände und des Kreuzungsfeldes zwischen Holzstrahlzellen und Tracheiden ist nicht erkennbar.

Beide Stammreste können bereits durch die im Querschnitt des Holzes unmittelbar nebeneinanderliegenden, verschieden großen Tracheiden von allen anderen Gymnospermen abgegrenzt werden. Dieses Merkmal findet sich nur bei Ginkgo-Holz und wird durch das Vorkommen von zwei in Länge und Durchmesser deutlich unterschiedlichen Tracheiden hervorgerufen. Die Erhaltung läßt eine artliche Bestimmung nicht zu.
Taxales

Zur Gattung Taxaceoxylon Kräusel \& Jain (Taxaceae) gehören zwei nur wenige Zentimeter lange Kieselholzbruchstücke aus der smeeiSchicht (mittl./ob. Kimmeridge) vom nordöstlichen Fuße des Lipogiro-Plateaus, etwa $18 \mathrm{~km}$ vom Tendaguru entfernt (Abb. 1, Nr. 4). Den Hölzern fehlen Harzgänge und sie zeigen im Querschnitt nur ganz schwach ausgebildete Zuwachszonen. Diese werden nur durch das Aneinandergrenzen von wenig unterschiedlich großen Tracheidenquerschnitten erkennbar. Die Tracheiden sind in streng radialen Reihen angeordnet und von meist rundlicher oder tangential ovaler bis rechteckiger Querschnittsform (Taf. 2: 1). Mit Maßen von radial $30 \mu \mathrm{m}$ und tangential bis $50 \mu \mathrm{m}$ sind die Tracheiden relativ kleinlumig. Auf den radialen Tracheidenwänden sind runde, einreihig übereinanderstehende Hoftüpfel vorhanden. Im Radialschnitt konnten gelegentlich Reste von Spiralverdickungen nachgewiesen werden. Das Holzparenchym liegt spärlich zerstreut in der Grundmasse des Holzes. Die Holzstrahlen sind einreihig und 1-10 Zellen hoch (Taf. 2: 2). Die Strahlzellen sind kreisförmig und mit Durchmessern von höchstens $15 \mu \mathrm{m}$ sehr klein. Die horizontalen Wände sind glatt (keine Abietineen-Tüpfelung), während auf dem Kreuzungsfeld zwischen Strahlzellen und Tracheidenwand taxodioide Tüpfel vorhanden sind.

Das für die Bestimmung wichtigste Merkmal sind die an einigen Stellen des Holzgewebes noch erhaltenen Reste der spiralverdickten Tracheidenwände. Im Holz rezenter Koniferen kommen spiralverdickte Tracheiden bei den Pinaceen, Taxaceen und Cephalotaxaceen vor. Die Pinaceen-Gattungen mit spiralverdickten Tracheiden (Pseudotsuga, Larix und einige Picea-

Tafel 2. 1. Taxaceoxylon sp. (Inv.-Nr. 1999/596), Querschliff, schwarzi-Schichten (?Apt), Niongala-Forst gegenüber Kikundi, $75: 1$ (Balken $=200 \mu \mathrm{m})$. 2. Taxaceoxylon sp. (Ausschnitt aus Fig. 1), Radialschliff mit mehreren, mindestens 3 Zellen hohen Markstrahlen, Holz von Pilzen teilweise abgebaut, 115:1 (Balken $=100 \mu \mathrm{m}$ ). 3. Cycadoxylon sp. (Inv.-Nr. 1999/597) mit 4 Leitelementringen (4. Ring nur noch in Resten rechts oben erhalten, smeei-Schicht (ob. Kimmeridge), Lilahi zwischen Kindope und Mtapaia, 1:1. 4. Cupressinoxylon sp. (Inv.-Nr. 1999/598), Querschliff, zu beiden Seiten der teilweise abgebauten Holzstrahlen (Pfeil) sind die Tracheiden sekundär dunkel gefärbt, schwarzi-Schichten (?Apt) des Mikadi-Plateaus, 135:1 (Balken $=100 \mu \mathrm{m}$ ). 5. Ginkgoxylon sp. (Inv.-Nr. 1999/600), Querschliff, schwarzi-Schichten (?Apt), am Fuße des Mbambala bei Kihendiye, 115:1 $($ Balken $=100 \mu \mathrm{m})$. 6. Ginkgoxylon sp., Querschliff (Ausschnitt aus 5), zwischen großen Tracheiden sind deutlich kleinlumigere eingeschaltet, $230: 1($ Balken $=100 \mu \mathrm{m})$

Plate 2. 1. Taxaceoxylon sp. (Inv.-Nr. 1999/596), transverse section, Schwarzi-Beds (?Aptian), Niongala-forest opposite Kikundi, 75:1 (scale bar $=200 \mu \mathrm{m}$ ). 2. Taxaceoxylon $\mathrm{sp}$. (detail from fig. 1), radial section with some xylem rays, at least three cells high and secondary xylem partly destroyed by fungi, 115:1 (scale bar $=100 \mu \mathrm{m}$ ). 3. Cycadoxylon sp. (Inv.-Nr. 1999/597) with four rings of tracheids (the fourth ring is only partly preserved), Smeei-Beds (upper Kimmeridgian), Lilahi between Kindope and Mtapaia, 1:1.4. Cupressinoxylon sp. (Inv.-Nr. 1999/598), transverse section of both sides of partly destroyed xylem rays (arrowed) with dark coloured tracheids, Schwarzi-Beds (?Aptian) of the Mikadi-Plateau, 135:1 (scale bar $=100 \mu \mathrm{m}$ ). 5. Ginkgoxylon sp. (Inv.-Nr. 1999/600), transverse section, Schwarzi-Beds (?Aptian), from the foot of Mbambala, near Kihendiye, 115:1 (scale bar $=100 \mu \mathrm{m}$ ). 6. Ginkgoxylon sp., transverse section (detail from fig. 5). Cells with smaller lumen occur between the bigger tracheid cells, $230: 1($ scale bar $=100 \mu \mathrm{m})$ 


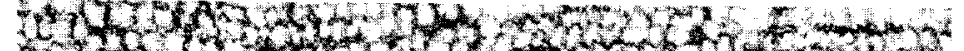

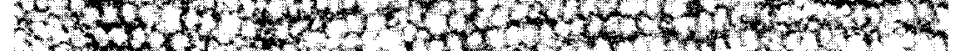

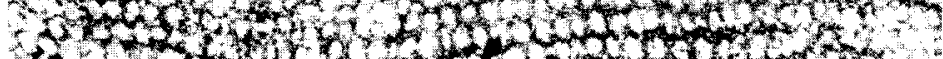

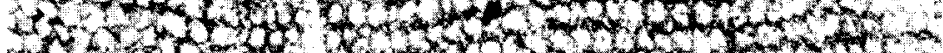

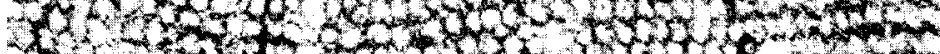

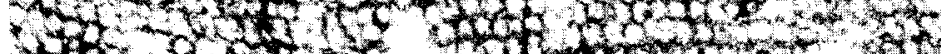

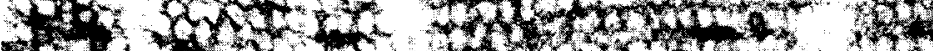

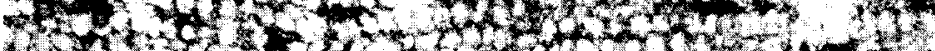

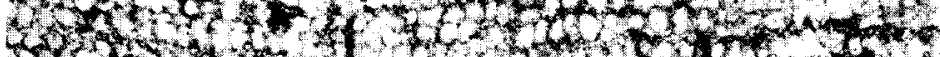

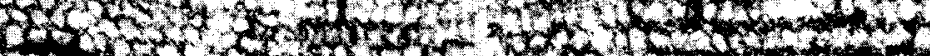

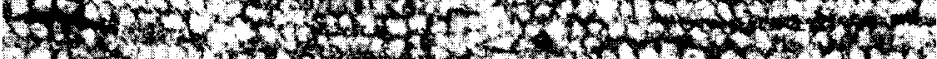

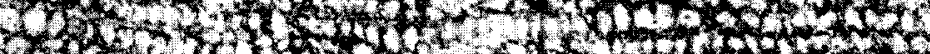

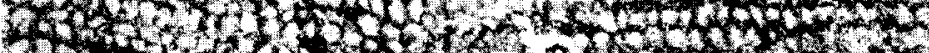

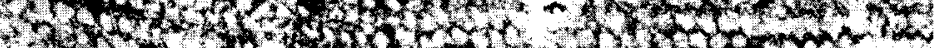

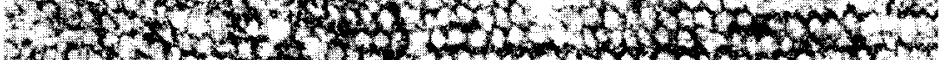

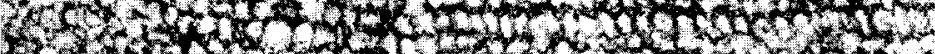

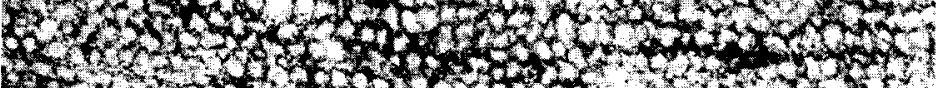

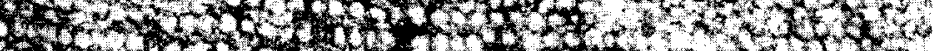

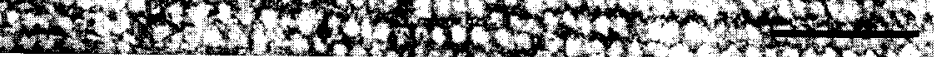

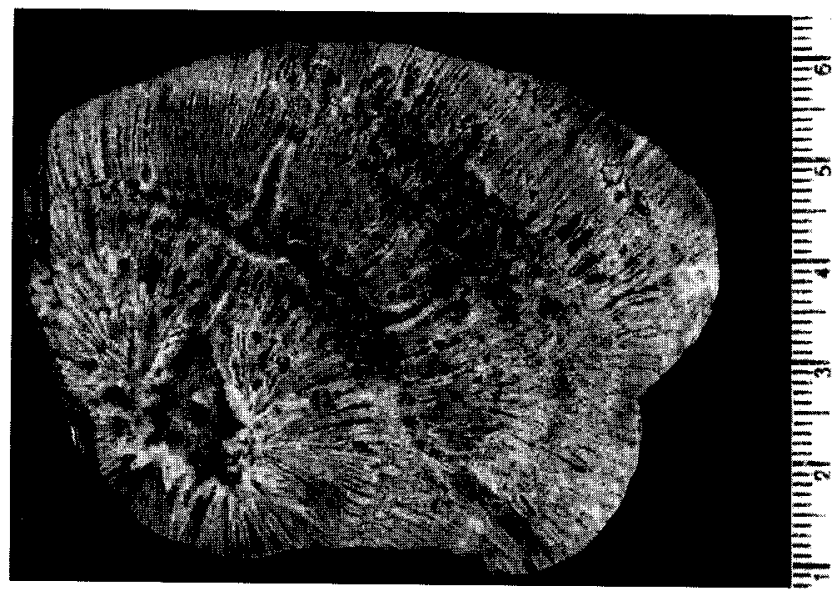

3

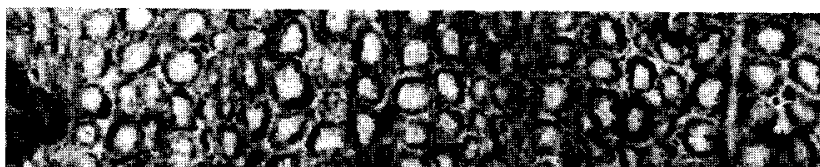

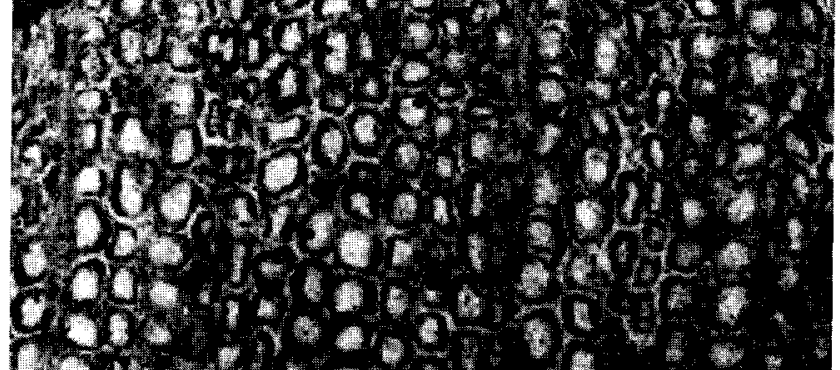

mod.

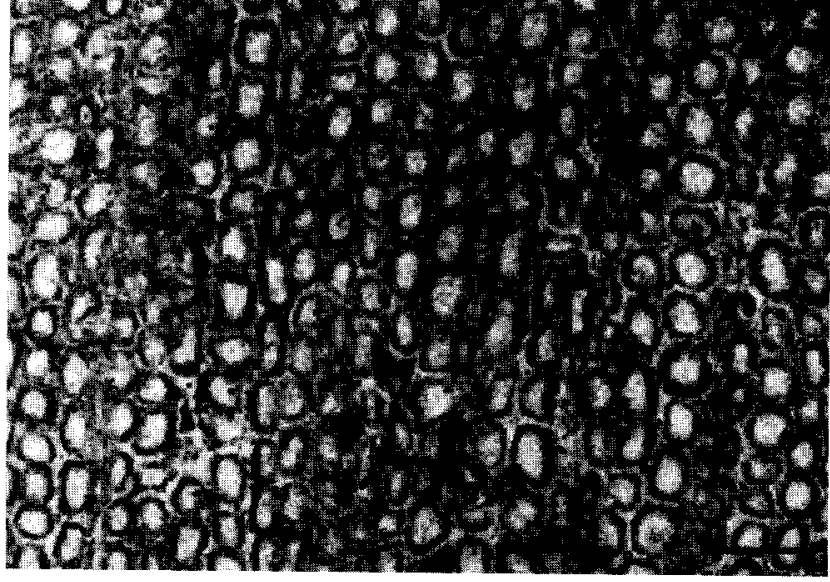

1

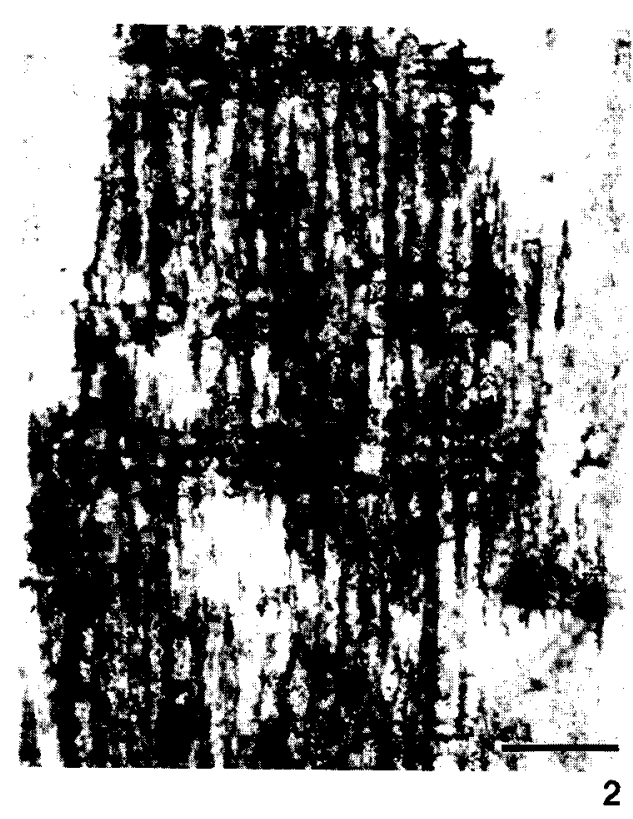

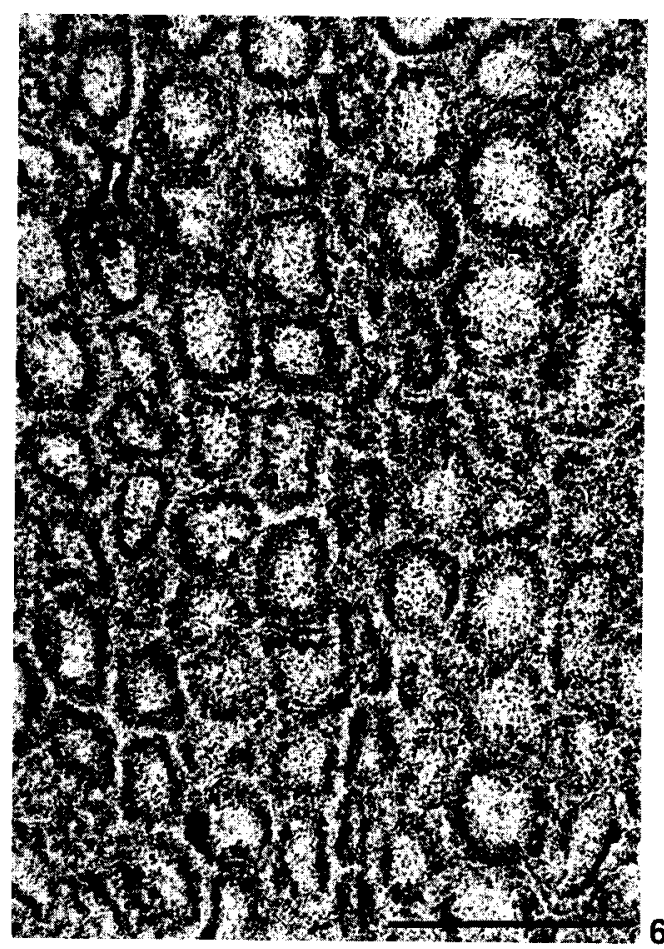


Arten) können durch ihre Harzgänge und die Abietineen-Tüpfelung der Strahlzellen ausgeschlossen werden. Das Fehlen der AbietineenTüpfelung und der Harzgänge weist auf die $\mathrm{Zu}$ gehörigkeit zum Holz der Taxaceen oder der Gattung Cephalotaxus. Somit kann das Holz ohne Zweifel zur Formgattung Taxaceoxylon gestellt werden.

Bisher wurden nur 11 Arten dieser Gattung aus dem Mesophytikum und Tertiär Ostasiens sowie 3 Arten aus dem europäischen Tertiär beschrieben. Nach Süss \& Velitzelos (1994) haben nur die Arten T. boureani (Greguss) Süss \& Velitzelos und $T$. biseriatum Süss \& Velitzelos die auch hier vorliegende Merkmalskombination „rundliche Tracheiden“ und „Holzparenchym vorhanden". Der stark fortgeschrittene Zellwandabbau durch holzzerstörende Pilze (Taf. 2: 2) macht es jedoch unmöglich, die beiden Hölzer einer dieser bereits bekannten Arten oder einer neuen Art zuzuordnen.

\section{Coniferales}

Die fossilreichen Schichten der mittleren SaurierMergel (tieferes Kimmeridge) vom KitukitukiBach in der Umgebung des Tendaguru (Abb. 1, Nr. 6) lieferten neben Invertebraten auch Kutikulen und Fusite. Ein Fusitbruchstück, vergesellschaftet mit den massenhaft in diesem Mergel auftretenden Cyrenen, zeigt die Merkmale von Glyptostroboxylon Conwentz (Taxodiaceae).

Das Holz ist ohne Harzgänge und zeigt schwach ausgeprägte Zuwachsgrenzen, die auf dem Querbruch nur durch das Aneinandergrenzen von kleinerlumigen an größerlumige Tracheiden angezeigt werden. Die überwiegend quadratischen bis rechteckigen Tracheiden sind in strengen radialen Reihen angeordnet. Die radialen Tracheidenwände sind mit relativ großen, einreihig locker übereinander stehenden Hoftüp- feln besetzt (abietoide Anordnung), kleinere Hoftüpfel kommen auf den tangentialen Wänden vor. Holzparenchym ist nicht oder nur spärlich zerstreut vorhanden. Die Holzstrahlen sind einreihig und 1-5 Zellen hoch (Taf. 1: 5), ihre horizontalen und tangentialen Wände sind dünn und glatt (keine Abietineen-Tüpfelung). Im Kreuzungsfeld zwischen Strahlzellen und Tracheidenwänden befinden sich 2-15 kleine, sehr dicht stehende, eiförmige bis runde glyptostroboide Tüpfel (Taf. 1: 6).

Das für die Bestimmung wichtigste Merkmal des vorliegenden beschriebenen Fossils sind die glyptostroboiden Tüpfel auf dem Kreuzungsfeld. Dadurch kann das Holz dieser Gattung von allen anderen Bautypen fossiler Koniferen unterschieden werden. Lediglich Circoporoxylon Kräusel hat ähnliche Kreuzfeldtüpfel. Jedoch sind bei den Arten dieser Gattung die mehr oder weniger kreisförmigen Tüpfel im Kreuzungsfeld stets einfach, d.h. ohne Höfe ausgebildet. Von Glyptostroboxylon sind bisher nur zwei Arten bekannt, die mit dem Holz der rezenten Gattungen Glyptostrobus und Cunninghamia verglichen werden können. Nach unseren vorläufigen Untersuchungen handelt es sich bei dem Fusit vom Tendaguru aufgrund der zahlreichen Kreuzfeldtüpfel (bis 13 Tüpfel im Kreuzfeld) um eine neue Art.

Ebenfalls aus den schwarzi-Schichten (?Apt) des Mikadi-Plateaus, etwa $25 \mathrm{~km}$ östlich des Tendaguru (Abb.1, Nr. 5), stammt der Lesestein (etwa $5 \mathrm{~cm}$ lang, mit einem Durchmesser von $4 \mathrm{~cm}$ ) eines verkieselten Cupressinoxylon Goeppert (Cupressaceae). In radialen Reihen angeordnete Tracheiden bilden die Grundmasse des Holzes. Sie haben meist quadratische bis rundliche, gelegentlich auch rechteckige Querschnittsformen (Taf. 2: 4). Zuwachszonen sind nicht vorhanden. Die Tracheidenlängswände sind mit runden, einreihig übereinanderstehenden Hoftüpfeln besetzt.

Tafel 3. Alle Kutikulen stammen aus dem Cyrenen-Mergel der mittleren Saurier-Mergel (oberes Kimmeridge) vom Kitukituki-Bach. 1. Kutikule Typ A, unregelmäßiges Zellmuster, Stomata statistisch verteilt, 230:1 (Balken = 100 $\mu \mathrm{m})$. 2. Kutikule Typ A, einzelnes Stoma, Spaltöffnungsapparat herausgefallen (oder nicht erhalten), 6 Papillen ragen über die äußere Atemhöhle, 460:1 (Balken $=50 \mu \mathrm{m})$. 3. Kutikule Typ A, Zellen mit leicht ondulierten Antiklinalwänden, partiell stärker kutinisiert und in ein Haar auslaufend (Pfeil), 460:1 (Balken =50 $\mu \mathrm{m}$ ). 4. Kutikule Typ A, Zellen mit einzelner ?Drüse (Pfeil), 460:1 (Balken $=50 \mu \mathrm{m})$. 5. Kutikule Typ B, deutlich gereiht stehende Stomata mit kräftig entwickelten Nebenzellen, Stoma-freie Zonen markieren den Verlauf der Blattadern, 115:1 (Balken $=100 \mu \mathrm{m})$. 6. Kutikule Typ B, 2 Stomata, deren Nebenzellen sich berühren, REM-Aufnahme, $750: 1$

Plate 3. All specimens are from the Cyrena-Marl of the Middle Saurian Beds (upper Kimmeridgian) from the Kitukitukibrook. 1. Cuticle type A, irregular cellular tissue, stomata regularly distributed, $230: 1$ (scale bar $=100 \mu \mathrm{m}$ ). 2. Cuticle type A, a single stoma lacking the stoma-apparatus (or not preserved), six papillae shelter the outer stoma-chamber, 460:1 (scale bar $=50 \mu \mathrm{m})$. 3. Cuticle type A, cells with slightly undulating anticlinal walls, strongly cutinisied in part and tapering up into a hair (arrowed), 460:1 (scale bar $=50 \mu \mathrm{m})$. 4. Cuticle type A, cells with a ?gland (arrowed), 460:1 (scale bar $=50 \mu \mathrm{m})$. $\mathbf{5}$. Cuticle type B, clearly aligned stomata with strongly developed guard cells. The stoma-free zones show the course of the veins, $115: 1($ scale bar $=100 \mu \mathrm{m})$. 6.Cuticle type B, two stomata with guard-cells touching one another, SEM, 750:1 

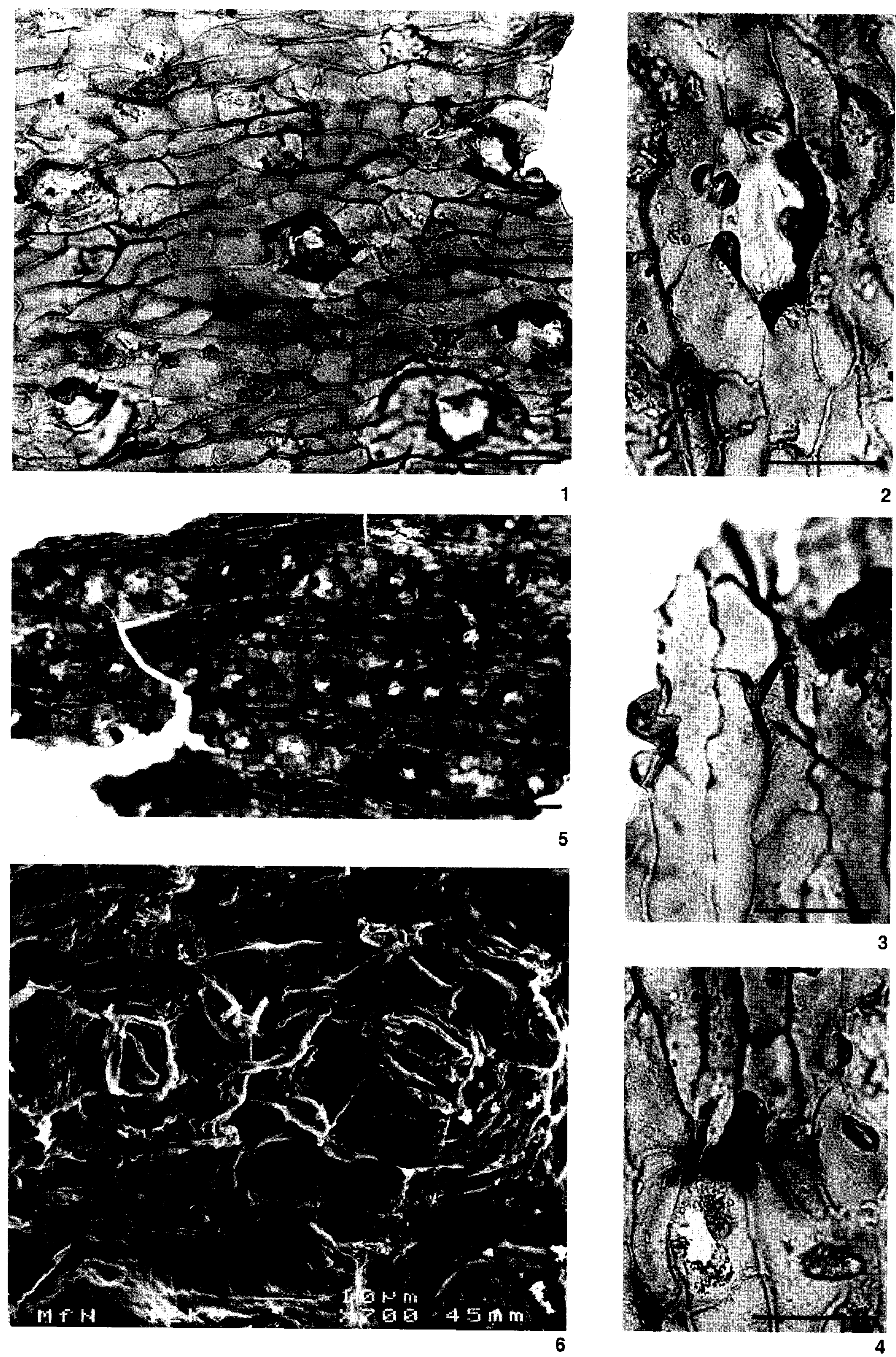
Das Holzparenchym liegt spärlich zerstreut in der Grundmasse des Holzes. Die Holzstrahlen sind ein- bis partiell zweireihig und 1-12 Zellen hoch. Die Kreuzfeldtüpfelung ist cupressoid, die Anzahl der Tüpfel ist nicht feststellbar. Bei dem bereits stark abgebauten Holz sind auf dem Querschnitt nur schmale, meist dunkel gefärbte Holzpartien zu beiden Seiten der Holzstrahlen erhalten. Das Restgewebe zwischen den Strahlen ist vollkommen zerstört. Große Fraßgänge von ?Arthropodenlarven (bis $5 \mathrm{~mm}$ im Durchmesser) sind in allen drei Schnittebenen vorhanden. Das Fossil kann vor allem wegen der cupressoiden Tüpfel im Kreuzungsfeld zwischen Holzstrahlzellen und Tracheiden zur Formgattung Cupressinoxylon gestellt werden. Eine Bestimmung bis zur Artzugehörigkeit ist nicht möglich. Das Auftreten einreihig übereinanderstehender Hoftüpfel auf den Tracheidenlängswänden schließt die Zugehörigkeit zu Protocupressinoxylon aus. Dieser im oberen Jura sehr häufige Holztyp konnte damit bisher am Tendaguru nicht nachgewiesen werden.

\section{Die Kutikulen}

Von allen bisher näher untersuchten Proben sind die Cyrenen-Mergel vom Kitukituki-Bach (Abb.1, Nr. 6) die fossilhöffigsten. Obwohl die naturmazerierten Kutikulenfetzen oft nicht sehr gut erhalten sind, zeigen sie doch eine Reihe interessanter Merkmale. Die Schließzellen sind meist herausgefallen (oder waren so schwach kutinisiert, daß sie nicht erhalten sind), sodaß sich die Organisation des gesamten Schließzellenapparates nicht mehr rekonstruieren läßt. Selbst eine grobe Zuordnung zu übergeordneten taxonomischen Einheiten ist aufgrund der für diesen bio- geographischen Raum fehlenden Vergleichsmöglichkeiten nur schwer möglich. Nach Lemoigne 1988 stellt sich für den höheren Jura bei der Mikroflora eine Ähnlichkeit mit der von Europa ein, was dadurch die Möglichkeit eröffnet, auch mit eurasischen Florenelementen zu vergleichen. Alle bisher präparierten Kutikulen stammen offensichtlich von Gymnospermen.

\section{Typ A}

Die Kutikule ist relativ zart und die meist geraden Antiklinalwände der Epidermiszellen können gelegentlich auch leicht gewellt sein. Sie sind mit 70 bis $170 \mu \mathrm{m}$ Länge und 15 bis $20 \mu \mathrm{m}$ Breite deutlich längsgestreckt. Die haplocheilen Stomata stehen vereinzelt, gelegentlich deutet sich eine weitständige Reihung an (Taf. 3: 1). Sie sind monozyklisch und verlaufen in Längsrichtung. 5 bis 6 papillöse Nebenzellen umgeben den Porus. Die Nebenzellen sind etwas größer und gedrungener als die unspezialisierten Epidermiszellen. Kräftiger kutinisierte Papillen ragen über den Bereich des Spaltöffnungsapparates und überdecken ihn etwa zur Hälfte (Taf. 3: 2). Eine Kutikule mit gleich gebautem Nebenzellenapparat zeigt ein Muster aus sehr viel gedrungeneren Zellen (etwa $60 \mu \mathrm{m}$ Länge bei $30 \mu \mathrm{m}$ Breite). Scheinbar wahllos verstreut treten Antiklinalwände auf, die in Längsrichtung stärker kutinisiert sind und teilweise kurze, leistenförmige Papillen bilden. Vereinzelt treten einzellige, kurze Haare (Taf. 3: 3) und drüsenartige Bildungen (Taf. 3: 4) auf.

Dieser Kutikulentyp findet sich in vergleichbarer Ausbildung bei einigen Koniferen (z. B. Tritaenia, Wilde 1991), könnte aber auch auf Ginkgoaceae hinweisen (z. B. Ginkgo huttoni Tralau 1968)

Tafel 4. Alle Kutikulen stammen aus dem Cyrenen-Mergel der mittleren Saurier-Mergel (oberes Kimmeridge) vom KitukitukiBach. 1. Kutikule Typ E, einzelner Stomastreifen mit eng stehenden Stomata, Antiklinalwände kräftig kutinisiert, 230:1 (Balken $=100 \mu \mathrm{m})$. 2. Kutikule Typ E (Ausschnitt aus 1), Nebenzellen mit kräftigen, kleinen Papillen, Antiklinalwände der Kranzzellen bis $5 \mu \mathrm{m}$ breit, $460: 1$ (Balken $=50 \mu \mathrm{m})$. 3. Kutikule Typ D, schwach kutinisierte, unregelmäßig bis gereiht angeordnete Zellen, Stomata frei verteilt, 115:1 (Balken $=100 \mu \mathrm{m}$ ). 4. Kutikule Typ D (Ausschnitt aus 3), Stoma mit ringförmiger Verstärkung der Antiklinalwände um die äußere Atemhöhle herum, von den Nebenzellen Kutinzapfen nach außen abgehend (Pfeil), 460:1 (Balken =50 $\mu \mathrm{m}$ ). 5. Kutikule Typ C, unregelmäßig angeordnete (links) und weitgehend gereiht stehende (rechts) Zellen mit weitgehend parallel ausgerichteten Stomata, 230:1 (Balken $=100 \mu \mathrm{m})$. 6. Kutikule Typ C (Ausschnitt aus 5), Stoma, Nebenzellen unterscheiden sich kaum von den unspezialisierten Epidermiszellen, äußere Atemhöhle von zwei Vorhofleisten überragt (Pfeil), 460:1 (Balken $=50 \mu \mathrm{m})$

Plate 4. All specimens from the Cyrena-Marl of the Middle Saurian Beds (upper Kimmeridgian) from the Kitukituki-brook. 1. Cuticle type E, single row of stomata in closed position. The anticlinal walls are strongly cutinised, $230: 1$ (scale bar = $100 \mathrm{um}$ ). 2. Cuticle type E (from fig. 1), guard cells with small strong papillae. The anticlinal walls of the neighbouring cells are $5 \mu \mathrm{m}$ in breath, $460: 1$ (scale bar $=50 \mu \mathrm{m}$ ). 3. Cuticle type $\mathrm{D}$, poorly cutinised, partly irregural arranged and partly stoma rows, $115: 1$ (scale bar $=100 \mu \mathrm{m}$ ). 4. Cuticle type D (from fig. 3), stoma with ring-shaped cutinisation of the anticlinal walls around the outer stoma-chamber. Cutinisation tapers from the guard cells into the space between the neighbouring cells (arrowed), 460:1 (scale bar $=50 \mu \mathrm{m})$. 5. Cuticle type C, irregular (left) and poorly aligned (right) cells with parallel positioned stomata, 230:1 (scale bar $=100 \mu \mathrm{m})$. 6. Cuticle type $C$ (detail from fig. 5), stoma. Guard cells are very similar to unspecialized neighbouring cells and the outer stoma-chamber is overlapped by paired lips (arrowed), $460: 1$ (scale bar $=50 \mu \mathrm{m}$ ) 

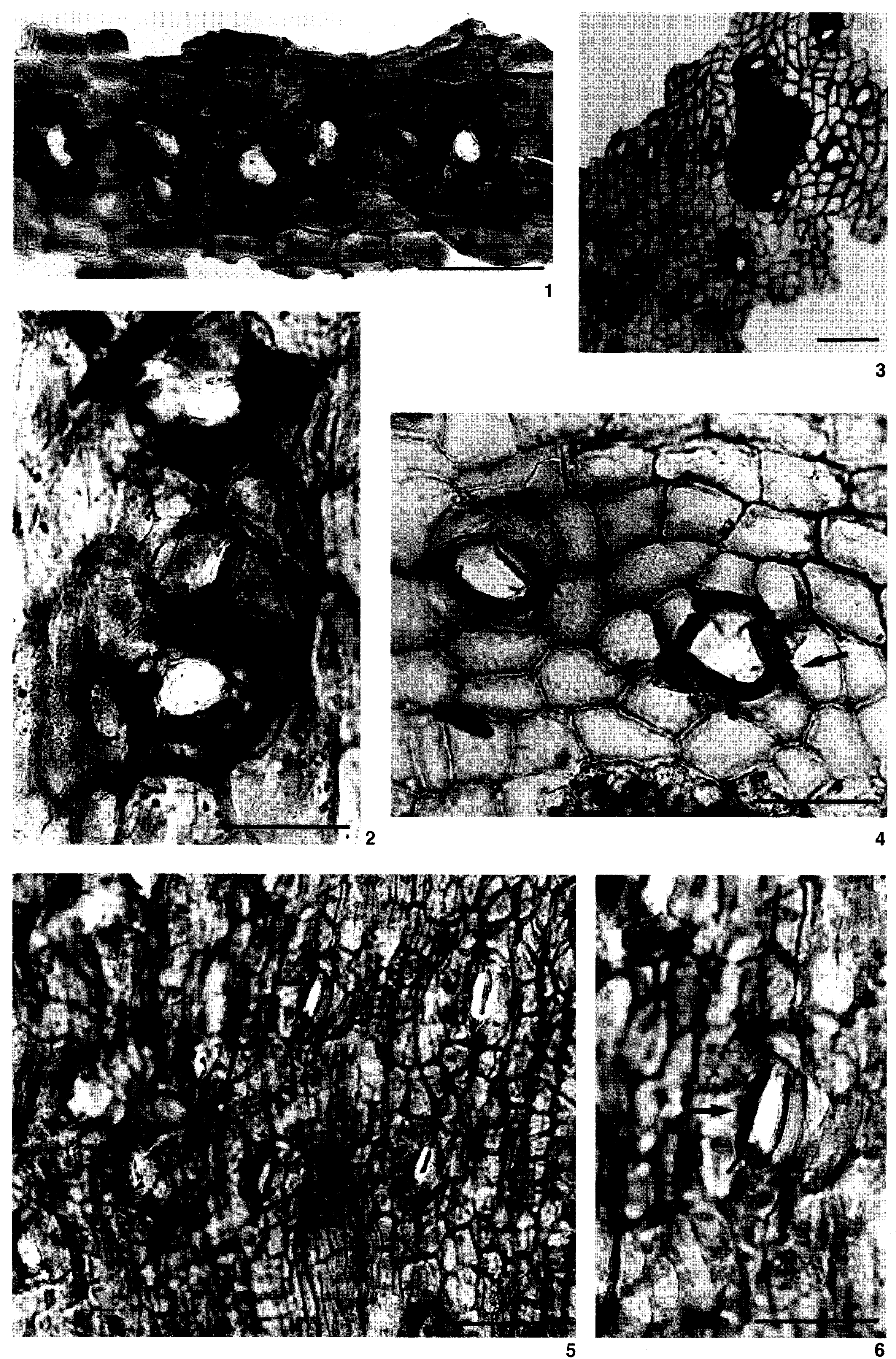


\section{Typ B}

Kräftig kutinisierte, stomafreie Zonen, die fast parallel nebeneinader verlaufen und sich gelegentlich spitzwinklig gabeln, charakterisieren diesen Kutikulen-Typ. Die Epidermiszellen dieser Zonen sind langgestreckt, schmal (bis zu $140 \mu \mathrm{m}$ lang und $15 \mu \mathrm{m}$ breit). Dadurch unterscheiden sie sich deutlich von den mehr oder weniger isodiametrischen Zellen der dazwischen liegenden Felder mit Durchmessern um $40 \mu \mathrm{m}$. Eine generelle Orientierung dieser Zellen fehlt. Gereiht in diesem Zellmuster stehen Stomata, die oftmals die gesamte Breite zwischen den stomatafreien Zonen einnehmen (Taf. 3: 5). Der Abstand der Stomata untereinander variiert, gelegentlich stoBen sie direkt aneinander. 4 bis 5 Nebenzellen umschließen den Bereich, in dem der Spaltöffnungsapparat gesessen hat, wobei gelegentlich zwei polare Zellen ausgebildet sind. Die Nebenzellen sind kaum größer als die normalen Epidermiszellen und überragen die Epidermisoberfläche, wodurch sie eine wallartige Struktur um die Spaltöffnung bilden können (Taf. 3: 6). Sie tragen distal am Rand zur Atemhöhle hin meist jeweils eine kleine, rundliche Papille.

Ganz ähnlich gebaute Kutikulen zeigen senkrecht zu den elongierten Zellen der stomatafreien Zonen angeordnete, häufig längsovale Stomata. Möglicherweise idiokutikulare flächigleistenförmige Fortsätze, die einer Vorhofleiste entsprechen könnten, überdecken etwa zur Hälfte die äußere Atemhöhle. Die Nebenzellen und vor allem die Vorhofleisten sind etwas stärker kutinisiert als die normalen Epidermiszellen. Gelegentlich scheinen noch die eingesenkten Spaltöffnungszellen erhalten $\mathrm{zu}$ sein. Details lassen sich nicht erkennen. Die längsovale Form der Spaltöffnungen könnte auf die vollständigere Erhaltung der Spaltöffnungsapparate zurückzuführen sein. Möglicherweise handelt es sich auch um Variationen der Kutikulen, wie sie u. a. von Koniferen bekannt sind (Benda 1962).

\section{Typ C}

Der insgesamt kräftig kutinisierte, amphistomatische Kutikularest zeigt Ober- und Unterseite eines Blättchens, wobei die Dichte der Stomata auf der ?Oberseite etwas geringer ist. Das Muster aus gereiht stehenden, angedeutet isodiametrischen bis elongierten Zellen verbunden mit der geringeren Stomadichte könnten auf eine Blättchenoberseite hinweisen (Taf. 4: 5). Das
Zellmuster erscheint im Vergleich zur Unterseite der Kutikule recht regelmäßig. Die Zellen sind 15 bis $30 \mu \mathrm{m}$ lang und 12 bis $25 \mu \mathrm{m}$ breit. Sie stehen in kürzeren Längsreihen, wobei die Längsachse der einzelnen Zellen parallel oder senkrecht zur Reihung orientiert sein kann. Die Blattrandzellen sind mit durchschnittlich $33 \mu \mathrm{m}$ Länge und $11 \mu \mathrm{m}$ Breite etwas stärker ausgelängt und schmaler. Die Längsachsen dieser Zellen sind immer in Richtung der Zellreihen ausgerichtet.

Die Epidermiszellen der vermutlichen Unterseite erscheinen etwas größer und bilden mit ihren polygonalen, vielgestaltigen Umrissen ein unregelmäßiges Zellmuster. Der parallele Verlauf der Nervatur mit gelegentlichen, spitzwinkligen Gabelungen ist durch langgestreckte, stärker kutinisierte Zellen angedeutet. Die haplocheilen Stomata auf der Unter- und Oberseite sind gleich gebaut, meist in Längsrichtung orientiert und frei verteilt. Auf der vermutlichen Oberseite scheinen sie etwas weniger dicht $z u$ stehen. Meist 5 nicht zusätzlich stärker kutinisierte $\mathrm{Ne}$ benzellen umschließen die schmalen, längsovalen Spaltöffnungen. Kräftig kutinisierte Vorhofleisten überragen fast zeltartig die äußere Atemhöhle (Taf. 4: 6).

Unter den frühen Ginkgoalen finden sich im Formenkreis der Gattungen Baiera/Sphenobaiera Kutikulen, die vor allem vom Bau und der Verteilung der Stomata her den oben beschriebenen nahe stehen könnten (Florin 1936).

\section{Typ D}

Eingestreut in ein Zellmuster aus relativ schwach kutinisierten, leicht gereiht stehenden Zellen treten gehäuft haplocheile Stomata auf (Taf. 4: 3). Die dünnwandigen, isodiametrischen bis polygonalen Zellen sind zwischen $25 \mu \mathrm{m}$ und $50 \mu \mathrm{m}$ lang sowie zwischen $16 \mu \mathrm{m}$ und $25 \mu \mathrm{m}$ breit. 5 Nebenzellen ragen in die äußere Atemhöhle hinein und überdecken dadurch fast die Hälfte des Öffnungsbereiches. Die der äußeren Atemhöhle zugewandten Antiklinalwände der Nebenzellen sind stark kutinisiert, so daß eine breit ringförmige Verstärkung um den Spaltöffnungsapparat entsteht. Wo die Nebenzellen aneinanderstoßen, verlaufen kräftige kurze Kutinzapfen nach außen (Taf. 4: 4). Solche Kutinzapfen konnten unter dem ostafrikanischen Material bisher nur an diesem Kutikulentyp festgestellt werden. Möglicherweise handelt es sich hier um eine Konifere. 
Typ E

Von diesem Typ wurde bisher nur ein Kutikulenrest mit einem Stomastreifen präpariert. $\mathrm{Zu}$ beiden Seiten der stomatatragenden Zone zieht sich ein vermutlich stomatafreier Streifen entlang, der von 40 bis $80 \mu \mathrm{m}$ langen und etwa $23 \mu \mathrm{m}$ breiten, sehr kräftig kutinisierten Zellen gebildet wird (Taf. 4: 1). Die stomatragende Zone ist kaum breiter als die Stomata. Neben der Stomatareihe und der stomatafreien Zone ist höchstens eine Zellreihe und zwischen den einzelnen Stomata sind kaum mehr als 4 Zellen ausdifferenziert. Diese Zellen sind isodiametrisch bis polygonal bei einer Länge von 35 bis $47 \mu \mathrm{m}$ und einer Breite von ungefähr $32 \mu \mathrm{m}$. Die Stomata stehen teilweise so dicht, daß sich die Nebenzellen der benachbarten Spaltöffnungsapparate direkt berühren. 5 - seltener 4 - Nebenzellen umschließen die Spaltöffnung. Sie überdecken nur mit einem sehr schmalen Kranz die äußere Atemhöhle. Die Zellen sind wenig stärker kutinisiert als die normalen Epidermiszellen und heben sich deutlich über die Oberfläche der Kutikule hinaus. An der höchsten Stelle, am Rand zur äußeren Atemhöhle hin, trägt jede Nebenzelle eine kräftige, kleine Papille (Taf. 4: 2). Die an die lateralen Nebenzellen angrenzenden Epidermiszellen haben mit über $5 \mu \mathrm{m}$ Breite auffällig stark kutinisierte Wände. Sie verbinden die nicht direkt aneinanderstoßenden Nebenzellen benachbarter Stomata und bilden dadurch ein kompaktes Stomataband.

Die kleinen, aufgesetzten Papillen der Nebenzellen sowie die Anordnung der Stomata ähneln sehr den Kutikulen von einigen Araucariaceen und vor allem Cheirolepidaceen. Vergleichbare Formen werden von Doludenko \& Askasova 1972 bei ursprünglichen Ginkgoalen aus dem Formenkreis um Sphenobaiera beschrieben.

\section{Schlußfolgerungen}

Das für diese paläobotanische Arbeit zur Verfügung stehende Probenmaterial ist für repräsentative Aussagen ungeeignet. So ergibt die Auswertung, daß die wenigen deutbaren Pflanzenreste auf einen relativ monotonen Bestand von Gymnospermen im meeresnahen Lebensraum der Saurier vom Tendaguru hindeuten. Eine unwiderlegbare Zuordnung der Kieselhölzer zu bestimmten Horizonten ist nicht mehr möglich, ihre Herkunft aus dem Gesamtprofil darf aber als gesichert angenommen werden, zu- mal die Holzreste typische Elemente des Mesophytikums wie Ginkgophyten und Cycadeen belegen. Sie deuten auf eine höhere Diversität der Flora vom Tendaguru hin, als auf den ersten Blick vermutet werden könnte. Da gerade die Cycadeen in calcitischer bzw. dolomitischer Erhaltung vorliegen, ist ihre Überlieferungsfähigkeit im Verhältnis zu den Kieselhölzern nicht sehr hoch. Trotzdem hatte bereits Borchardt auf einer seiner Expeditionen 1897 nur 40 km nordöstlich des Tendaguru in Jura/Kreide-Grenzschichten ein Cycadeenholz aufgesammelt (Inv.Nr. 1986/340 des MfN). Man darf daraus wohl schließen, daß u. a. diese Pflanzengruppe bei dem bis jetzt vorliegenden Material deutlich unterrepräsentiert ist.

Die Fusite der mittleren Saurier-Mergel zeigen ein noch eintönigeres Bild, bestehend aus bis jetzt nicht näher bestimmbaren Koniferen und einer Taxodiacee. Es handelt sich um die bisher nur sehr selten nachgewiesene Gattung Glyptostroboxylon, die dem Holz von Koniferen (Glyptostrobus und Cunninghamia) zugeordnet wird, die im feuchten Milieu von Flußauen und Niederungen wachsen. Glyptostrobus charakterisiert im Tertiär sogar die Basis der palustrinen Sukzession in Braukohlenmooren (Mai 1995).

Eine solche Konzentrierung und damit verbundene Reduzierung der einstigen Flora auf die Holzkörper von Koniferen bzw. Gymnospermen war zu erwarten, weil vor allem nach längerem Transport gerade bei Fusiterhaltung nur noch die widerstandsfähigsten Reste der ehemaligen Flora überlieferungsfähig sind.

Die Kutikulen sind aufgrund fehlender Vergleichsmöglichkeiten und der bisher fehlenden Makroflora aus dem ostafrikanischen Bereich keiner bestimmten Gattung zuzuordnen. Die nur aus wenigen Stichproben gewonnenen 5 Kutikulen-Typen weisen fast alle stark kutinisierte Epidermen, auf jeden Fall aber eingesenkte und z. T. mit Papillen umgebene Stomata auf. Verteilung, Größe und Bau der Spaltöffnungen und der Epidermiszellen lassen bei den Kutikulatypen $\mathrm{C}$ und $\mathrm{E}$ an Pflanzen aus dem Formenkreis Sphenobaiera denken (Florin 1936, Doludenko \& Askasova 1972). Auf jeden Fall sind für die Kutikulen Ginkgophyten als Erzeuger nicht auszuschließen, was auf zumindest leicht trockene Standorte hindeutet. Xerophytische Merkmale allgemein könnten allerdings auch nur auf etwas ungünstige Bodenbedingungen - z.B. fehlende Belüftung oder leichte Salinität - verweisen. Lemoigne 1988 spricht von einer deutlichen $\mathrm{Zu}$ nahme der Koniferen bei gleichzeitigem Zurück- 
gehen von Pteridophyten im afrikanischen Bereich südlich der Paläotropen. Das dürfte für ein etwas weniger feucht-warmes Klima an der Wende Jura/Kreide im östlichen Afrika als zur Zeit des tieferen Jura sprechen, ist aber nicht als Beleg für Aridität zu werten.

Auffällig ist die verarmte Flora darüberhinaus durch das völlige Fehlen von Hinweisen auf azonale Florenelemente, die sich gewöhnlich auch in arid angepaßten Florengemeinschaften finden. Dies ist ein weiterer Hinweis darauf, daß das vorliegende, ungewöhnlich monotone Florenbild nicht den tatsächlichen Verhältnissen zur Zeit des oberen Jura entspricht. Daß eine Krautschicht existierte, belegen die wenigen Sporenfunde von Pteridospermen und Moosen. Alle diese Befunde lassen darauf schließen, daß bei gezielt vor Ort entnommenen Proben eine weitaus größere Anzahl verschiedener Pflanzengruppen entdeckt wird. Damit wird man ein vollständigeres Bild der Diversität der Flora im Grenzbereich Jura/Kreide Ostafrikas gewinnen können.

Alle Pflanzenreste sind über weite Strecken transportiert und in ein relativ grobkörniges, d. h. siltig-sandiges Sediment, in wahrscheinlich brakkisch-mariner Flachwasserfazies eingeschwemmt worden. So konnten unterschiedlichste Abbauprozesse (Wechsel im aquatischen Milieu, möglicherweise auch Trockenfallen mit anschließendem Windtransport) über einen langen Zeitraum auf die pflanzlichen Reste einwirken. Daneben kam es zu einer sehr starken Zerkleinerung und Selektion. Als Folge blieben nur Reste erhalten, die besonders holz- und harzreiche Gewebe sowie kräftig kutinisierte Epidermen aufweisen und das sind in aller Regel Koniferen.

Im gleichen Florengürtel wie Ost-Afrika liegende Fossilvorkommen in Indien und Südamerika zeigen im höheren Jura eine deutliche Zunahme von Koniferen-Taxa, Pteridophyten sind aber für das Bild zumindest deutlich mitbestimmend (Lemoigne 1988). Im oberen Jura des südlichen Afrika und Madagaskar, wohin auch auf der Basis der Palynologie Beziehungen nachweisbar sind (freundl. mündl. Mitt. Schrank 1999), bestimmen die Filicales das Florenbild, wenngleich Koniferen auch nicht selten sind (Lemoigne 1988). Biogeographische Beziehungen nach Südafrika und Madagaskar wurden bereits von Dacqué \& Krenkel (1909) sowie Zwierzycki (1914) aufgrund der Ähnlichkeiten des paläozoologischen Materials vermutet.

Bei dem untersuchten Material muß berücksichtigt werden, daß fast ausschließlich Proben vorliegen, die auch kalkschalige Invertebraten oder Knochenreste lieferten. Besser erhaltene Pflanzenreste wären aber nur in Sedimenten aus festländischen, humus-sauren Stillwasserbereichen zu erwarten, in denen kalkige Innen- oder Außenskelette für gewöhnlich nicht überlieferungsfähig sind. Der hohe Tonanteil der Sedimente solcher Faziesräume führt zu besonders schlechten, natürlichen Aufschlußbedingungen, was wiederum die Fund- und Sammlungsmöglichkeiten einschränkt. Weit verbreitet sind solche Ablagerungen innerhalb des Profils am Tendaguru scheinbar nicht, doch weist Janensch (1914) zumindest an der Basis der mittleren Saurier-Mergel auf eine tonige Lage hin. Leider scheinen von dieser tonigen Lage keine Proben zu existieren, obwohl auch hier Knochenreste gefunden wurden. So dürfte die Ausrichtung der Sammlungstätigkeit in Verbindung mit den Aufsammlungsmöglichkeiten eine zusätzliche, starke Verzerrung des Bildes der ehemaligen Flora während dieses Abschnitts der Erdgeschichte bewirken.

Da ein Teil der Abfolgen am Tendaguru möglicherweise fluviatil-lakustrisch dominiert ist, muß mit engräumigen lateralen und vertikalen Faziesänderungen gerechnet werden. Um den ehemaligen Lebensraum der Saurier auch nur annähernd rekonstruieren zu können, müßten daher zuerst mehrere detaillierte lithologische Profile aufgenommen werden, die anschließend stratigraphisch möglichst genau einzustufen sind. Erst auf dieser Basis wird es möglich sein, ein differenzierteres Bild der spätjurassischen Flora des östlichen Afrika zu entwickeln und phytogeographische Beziehungen genauer zu fassen.

\section{Danksagung}

Frau Dr. Elke Wäsch, Berlin, danken wir sehr herzlich für ihre Unterstützung und Betreuung bei der Erstellung der REM-Aufnahmen und Dr. David Unwin, Berlin, für die Durchsicht der englischen Textpassagen. Frau Waltraud Harre, Berlin, ist für ihre phototechnischen Bemühungen sowie Herrn Jörg-Peter Mendau, Berlin, für die Durchführung der Zeichenarbeiten zu danken.

\section{Literatur}

Aitken, W. G. 1961. Geology and Palaeontology of the Jurassic and Cretaceous of Southern Tanganyika. Part I. Bulletin of the Geological Survey of Tanganyika 31: $1-63$.

Benda, L. 1962. Beiträge zur Flora des nordwestdeutschen Wealden. II. Blattreste aus norddeutschen Tiefbohrungen. - Geologisches Jahrbuch 79: 737-782. 
Dacqué, E. \& Krenkel, E. 1909. Jura und Kreide in Ostafrika. - Neues Jahrbuch für Mineralogie, Geologie und Paläontologie 28: 150-232.

Dietrich, W. O. 1914. Die Gastropoden der Tendaguruschichten, der Aptstufe und der Oberkreide im südlichen Deutsch-Ostafrika. - Archiv für Biontologie 3, 4, 3: $101-153$.

Doludenko, M. P. \& Askasova, E. S. 1972. Ginkgoales and Czekanowskiales from the Irkutsk Basin. - Transactions of the Academy of Sciences of the USSR 230: 7-77.

Florin, R. 1936. Die fossilen Ginkgophyten von Franz-JosephLand. II. Allgemeiner Teil. - Palaeontographica 82 B: $1-72$.

Gothan, W. 1927. Ein araucarioider Coniferenzapfen aus den Tendaguru-Schichten. - Palaeontographica, Suppl. 7, II, 1, 3: 103-106.

Heinrich, W.-D. 1998. Late Jurassic Mammals from Tendaguru, Tanzania, East Africa. - Journal of Mammalian Evolution 5(4): 269-290.

- 1999. The taphonomy of dinosaurs from the Upper Jurassic of Tendaguru, Tanzania. - Mitteilungen aus dem Museum für Naturkunde, Geowissenschaftliche Reihe 2: $25-61$.

Hennig, E. 1914. Beiträge zur Geologie und Stratigraphie Deutsch-Ostafrikas. - Archiv für Biontologie 3, 3, 2: 1-72.

- 1937. Der Sedimentstreifen des Lindi-Kilwa-Hinterlandes (Deutsch-Ostafrika). - Palaeontographica, Suppl. 7, II, 2, 2: $1-99$.
Janensch, W. 1914. Die Gliederung der Tendaguruschichten im Tendagurugebiet und die Entstehung der Saurierlagerstätten. - Archiv für Biontologie 3, 3, 2: 225-261.

Lemoigne, Y. 1988. La flore au cours des temps géologiques. - Géobios, mém. spec. 10 (2): 296 pp.

Mai, D. H. 1995. Tertiäre Vegetationsgeschichte Europas. Jena, Stuttgart, New York (G. Fischer Verlag), 691 S.

Stockey, R. A. 1982. The Araucariaceae: An evolutionary perspective. - Review of Palaeobotany and Palynology 37: $133-154$.

Süss, H. \& Velitzelos, E. 1994. Ein neues fossiles Koniferenholz, Taxaceoxylon biseriatum sp. nov., aus tertiären Schichten der Insel Lesbos, Griechenland. - Feddes Repertorium 105: 257-269.

Tralau, H. 1968. Evolutionary trends in the genus Ginkgo. Lethaia 1 (1): 63-101.

Weaver, J. C. 1983. The improbable endotherm: the energetics of the sauropod dinosaur Brachiosaurus. - Paleobio$\operatorname{logy} 9(2): 173-182$.

Wilde, V. 1991. Tritaenia (al. Abiatites) linkii (Roemer) Mägdefrau \& Rudolf (Coniferae inc. sed.) und ihr Vorkommen in der Wealden-Fazies der unteren Kreide von Nordwestdeutschland. - Neues Jahrbuch für Geologie und Paläontologie, Abhandlungen 183 (1-3): 363-374.

Zwierzycki, J. 1914. Die Cephalopodenfauna der TendaguruSchichten in Deutsch-Ostafrika. - Archiv für Biontologie 3, 4, 3: 7-96. 